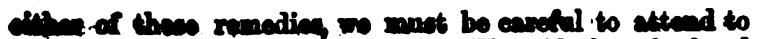
the common sense of the question. We said that the head of the verm was in tho ducdenum, or upper portion of the jejunam; now, of course, it is neceseary that the head should be left as far as poscible unproteoted by food, in order to allow the medicine to act more freely on it. The patient must, therefore, fast for at least twenty-four hours bafore taking the remedy. Again, as neither the fern nor tho kouseo are in themselves purgatives, a brisk dose of castor oil must be given a little while after the remedy itealf has been administered. In Africa, another fern is given, the aspidium athamanticum, and lately two other remedies have been added to our list, both natives of Africe, and both myrinaceous plants; these are, myrsine Africana, and mæsa picta. It would be curious to examine if there is any common chemical property in plants so widely different in botanical character as the pomegranate (myrtaces), brayera anthelmintica (rosaces), the two plants abore mentioned, and the aspidia, which should make them alike poisonous to these parasites.

Bothriocephalus latus may be distinguished from tænia solium with the greatest ease. The head is elongated, and instead of the four suckers, is provided with two sulci; the genital pores are also in the middle of each of the segments, and not at the sides, as in tania. The segments are also proportionably broader and shorter. This tepeworm is not found in England; it is, however, common in Switzerland and Russia; this local distribution of the parasite may perhaps help us to discover its origin, and it would be of interest to inquire if there be any peculiarity in the food of the inhabitants of those districts in which it occurs. It is a subject well worth attention, since if the clue to the cause of these pests be once known, it will be easy to prevent their occurrence.

We.shall leave the consideration of the trematoid worms, or flukes, and the nematoidea, for another day.

Birmingham, Angust 1855.

\section{A CASE OF ILEUS, FROM FIBROUS CANCER AT THE ENTRANCE OF THE CACUM.}

\section{By THOMAS SANDWITH, M.D.}

Os the 11th of June, I attended, in consultation with my friend Dr. Boulton, Mr. Wynn, an iron-founder, aged 42 years. He was of a meagre and emaciated habit, but was a man of considerable mental power. For some months, he had some difficulty in keeping his bowels regular.

The symptoms were at first those of a mild form of gastro-enteritis, and no fears were entertained of his speedy recovery. Defæcation was daily effected by mild aperients and an injection, which brought away a few dark green coloured scybala. A slight ptyalism being in a few days produced by alterative doses of hydrargyrum cum cretâ with Dover's powder, the medicine was discontinued.

Soon afterwards the costiveness became insuperable; nothing returned but the enemas. He complained of nausea, tormina, and spasmodic contractions of the abdominal muscles; and began to romit matter which had a stercoraceous appearance and a fæculent odour. The true character of the disease was now apparent, and the usual means were adopted to procure fæcal evacuations. He was bled to relaxation; tobacco enemas were administered at short intervals ; full doses of opium were given ; and generally speaking the plan of treatment recommended by the late Dr. Abercrombie of Edinburgh, in his excellent work on Diseases of the Abdominal Viscera, was adopted.

The patient was now seen by Sir Henry Cooper, of Hull, who approved of our proceedings.

On the failure of these measures, the long tube of the stomach-pump was carried up the colon; and the bowel being distended with warm water, the action of the instrument was reversed, so as to empty it completely. Bleeding ad deliquium, in the erect posture, was then tried, followed by a dechm of exoton oil in an cnems Gelranim emplojed for sererel days, cold aftuaion of the logs and belly, ice to the abdomen, and finally crude marcury, but all without effect.

The case was now left to nature, and our efforts were limited to means calculated to relieve pain and keep up the strength of the patient. He was fed with chicken-broth, beef-tea, and jellies, in small quantities at a time. A mild injection was given every morning; and twice a day boeftea and laudanum were administered per anum. These measures were approved of by Mr. Hewson, an eminent surgeon from Lincoln, who met us in consultation.

By this plan of treatment, he was rendered tolerably comfortable; the spasms and stercoraceous vomitings were less frequent; the latter occurring only once in two days; but there was a daily increase of emaciation. At length, at 1 o'clock, A.M., on the 22nd of July, six weeks from the date of the attack, having occasion to get up to the night table, he felt something give way, and became alarmingly ill. I found him moribund, the wrists cold, the jaw fallen, the pupils of the eyes dilated, and the face hippocratic. Being put to bed, cordials were administered; but he only partially rallied, and expired at half-past 11 o'clock, A.M.

All his medical attendants were agreed that the cause of obstruction was seated at the junction of the ileum and cæcum; but whether it was an intussusception, or the pressure of a tumour in that situation, was uncertain. As, however, the disease advanced, most of them were inclined to the latter supposition; the comparative mildness of the symptoms, and the duration of the complaint, being adverse to the notion of there being a volvulus. It has been observed, that what he vomited had a stercoraceous appearance and odour; but it was never supposed that the contents of the colon were ejected. We had indeed every reason to believe that it was perfectly empty. On this point, Morgagni has some pertinent remarks. "The ingesta", he observes, "which are conveyed downwards with the succus intestinalis, the succus pancreaticus, and the bile, and are delayed in the small intestines, especially if the parietes of the canal are inflamed, acquire the peculiar odour of stercoraceous matter, and may be called excrement without impropriety."* But, to return to the narrative, a post mortem examination revealed the following particulars.

The small intestines were immensely enlarged, while the cxcum was contracted, and the colon reduced to the normal dimensions of the small intestines. At the junction of the ileum and cæcum, the intestine was converted into a hard annular scirrhous tumour, resembling the gizzard of a forl, which adhered to the sacro-iliac juncture of the pelvis. It was thinner on the sacral aspect than on the upper; and the canal was so much narrowed as only to admit the passage of a large dissecting needle. There were several ulcers towards the termination of the ileum, from the largest of which issued the quicksilver that had been taken.

The alimentary canal, from the mouth to the anus, is the seat of fibro-cancer, or scirrhus, as it is commonly called. The ordinary situations of that disease are the lips, tongue, œsophagus, the cardiac and pyloric orifices of the stomach, and the rectum. I have, however, seen a cancerous tumour, about the size of a small orange, in the larger curvature of the stomach, and also in the sigmoid flexure of the colon, which was ulcerated and adherent to the bladder; so that ultimately fæces were voided with the urine. Two cases are on record of scirrhus of the cæcum;t and Nicholas Piso, as well as Rokitansky, mentions scirrhus as an occasional cause of ileus; but I have only met with one recorded case of this disease produced by a scirrhus of the entrance of the cæcum. The case occurred to the great Boerharve, and is related at length by Von Swieten, in his Commentaries.t The difference between cancer of the cæcum and its entrance is remarkable. In the former the - Cook's Yorgagni, vol. i, p. $55 . \quad+$ Copland's Dictionary, p. 280. 
caput-coli is enlarged, in the latter it is contracted; in the one the symptoms are allied to chronic dysentery, in the other to intuseusception.

Beverley, Yortshire, Angust 14th, 1855.

\section{DISLOCATION OF THE FEMUR ON THE DORSUM OF THE ILIUM, REDUCED EIGHT MONTHS AFTER DISARTICULATION.}

By H. F. GISBORNE, Esq., Surgeon to the Derbyshire General Infirmary.

Wruhrax Woodras, aged 45, of Newborough, Staffordshire, was admitted into the Derbyshire Infirmary, on the 1st of August, 1855, under my care, for a supposed prolonged case of sciatica. It appears that on the 20th of December, 1854, in crossing over a wooden bridge, he put his foot into a hole, got his body twisted, and fell. Surgical aid was obtained; but the nature of the accident not being correctly ascertained, he was leeched and blistered, etc., and continued under treatment for several months; as a last resource, he was sent to the hospital. On examination, the right thigh was partially flexed, and bent over the opposite limb, the toes resting on the instep of the other foot; the leg was shortened upwards of three inches, and was wasted from inaction; the head of the femur was distinctly felt on the ileum, but very little motion could be perceived. Woodings' general health seemed declining from treatment and confinement.

A consultation was called; and it was deemed right to attempt reduction.

On the 7th of this month, Woodings, under the influence of chloroform, had his thigh freely bent and rotated, to detach some of its new connections; gradual extension with pulleys was then made, and, in about fifteen minutes, it returned to its socket with an audible noise. The limb rotated, but the trochanter seemed to project more than the left one; this probably arose from the altered position and emaciation of the neighbouring muscles, and not improbably in part from the acetabulum having some deposit of new matter in it. The limb measured the same length as its fellow one; it was secured for some days with the long splint, and is now (August 18th) merely supported by a belt round the pelvis.

This case is altogether progressing most satisfactorily ; and is so far very encouraging to surgeons to attempt the replacement of dislocations after lengthened periods.

Derby, August 19, 1855.

\section{CASE OF A MAN SWALLOWING A HALF- SOVEREIGN.}

By G. MALLETT, Esq.

Ox the 17th of this month, a man, aged 26 years, put into his mouth a half-sovereign; a child play fully attempting to seize it, caused him to throw back his head; and, by so doing, the piece of money was precipitated into the larynx. Mr. Eames, an intelligent practitioner in the neighbourhood, was immediately sent for, and, finding such to be the case, requested further assistance. I was then summoned, and saw the patient about four hours after the accident

The man was breathing calmly and naturally; he had no wheezing, cough, or other distressing symptoms; but he said be felt an uneasiness about an inch below the thyroid cartilage; and, on placing the stethoscope over that portion of the trachea, a decided whistling in the respiration was heard. Taking into consideration the absence of all irritation, and in fact of all distressing symptoms, we decided that we should not be justified in opening the trachea until some cough and irritation had come on, in the hopes that the cough might be sufficient to dislodge the foreign body.

August 20th. He was much the same, except that the breathing was a little more whistling, accompanied with a alight degree of fever.
Anguat 21st. $A$ fit of coughing camo on Ho wh directed to put his head lower than the body, and the half sorereign was ejected by the cough. He has hid no unpleasant feeling since, and is in fact quite well.

RExakRs. I think the result proves that we were justified in deferring the operation-an operation cady enough to perform, but which is often attended with fatal results, either owing to the immediate effects of the operation, or more probably to the incurable nature of the disease for which it is performed.

Bolton-le-Moors, August 22nd, 1855.

\section{PFRISCOPIC REVIFW.}

\section{PRAGTTE OF MIEDTCLTE ATD PATHOLOGY.}

\section{GLEANINGS FROM THE JOURNALS.}

PATHOLOGY AND TREATHENT OF BERIBERI.

Dr. Morehead regards beriberi as a general dropsy of a complicated character, for the most part appearing when the vessels are tolerably full of blood, and a blood abounding in watery constituent, and following exposure to external cold. $\mathrm{He}$ is of opinion that the term ought to be expunged from medical literature, as likely to mislead by its indefiniteness; and he now seeks to remove some of the difficulties enveloping the subject by reducing it to known conditions.

$\mathrm{He}$ finds these conditions in the scorbutic diathesis. $\mathrm{He}_{\boldsymbol{\theta}}$ believes that the disease, more " particularly in its acute form, will be found to present itself in individuals favourably circumstanced for the development of a scorbutic taint, and who, while in this diathesis, have been exposed to the sudden cooling of the surface of the body from sudden alternations of tem. perature or of wet." Regarding the disease as one of general dropsy, Dr. Morehead suggests that the principles to be followed in its treatment should be the same as those guiding the treatment of general dropsy. According to this view, he explains the apparently conflicting statements made by various authors, of the advantage of the most opposite kind of treatment. Dr. Morehead admits the occurrence of cases justifying antiphlogistic treatment; but in the majority of instances, diuretics, stimulants, and vapour baths, are required. Four cases are brought forward, which confirm the views of Dr. Morehead, both by their previous history, the course of the disease, and the post mortem appearances. The persons affected were sailors, who, during an unexpectedly extended voyage, had been restricted to a poor diet, and much exposed to inclemency of the weather; while all those who in the same ship had been supplied with antiscorbutic food, had escaped the disease. The symptoms were edema of the lower extremities, causing a waddling gait, feeble pulse, scanty urine (not albuminous), uneasiness at epigastrium, moist tongue, gums discoloured but not swollen. The post mortem examination of two of the cases exhibited fluidity of the blood, and congestion of the liver; but no organic disease of any of the viscera. There was some serous effiusion in the arachnoid, pleura, and peritoneum. (Trans. of Mled. and Phys. Soc. of Bombay; and Brit. and For. Med.-Chir. Review, July 1855.)

ETIOLOGY OF ELEPHANTIASIS ARABUY.

Dr. Rignifr, in the Zeitschrift der $K$. K. Gesellschaft der Aerzte zu Wien, Heft 1, 1855, endeavours to show that ele phantiasis is not essentially a disease of tropical climates, bat that it may occur sporadically all over the globe, provided certain circumstances affect the patient by which the functions of the vascular system, and especially of the lymphatics, are impaired. To an alteration of the fnnctions of the latter, he attributes the hypertrophy of the cellular tissue and of the skin which constitutes the chief feature of the disease. In four cases of elephantiasis of a lower extremity, the commencement of the affection, which he always observed on the left side only, was marked by induration and swelling of the inguinal glands, indicating an arrest of their normal function. The author compares the disease to phlegmasis alba dolens, and to sclerosis neonatorum, which Henle has attributed to an extensive insufficiency of the lymphatics. In two adult healthy Turks that came under Dr. Rigler's notice, the disease, affecting their left feet, followed the occurrence of plague buboes. I case of 